\title{
Microbiology Susceptibility Method
}

National Cancer Institute

\section{Source}

National Cancer Institute. Microbiology Susceptibility Method. NCI Thesaurus. Code C87934.

The technique used to administer a microbiology susceptibility assessment. 